\title{
Analysis of Exhaust Plume Effects on Sonic Boom for a
}

\section{9-Degree Wing Body Model}

\author{
Raymond Castner ${ }^{1}$ \\ NASA Glenn Research Center, Cleveland, Ohio, 44135
}

\begin{abstract}
Reducing or eliminating the operational restrictions of supersonic aircraft over populated areas has led to extensive research at NASA. Restrictions are due to the disturbance of the sonic boom, caused by the coalescence of shock waves formed off the aircraft. Recent work has been performed to reduce the magnitude of the sonic boom $\mathrm{N}$-wave generated by airplane components with focus on shock waves caused by the exhaust nozzle plume. Previous Computational Fluid Dynamics (CFD) analyses showed how the shock wave formed at the nozzle lip interacted with the nozzle boat-tail expansion wave. The nozzle lip shock moved with increasing nozzle pressure ratio (NPR) and reduced the nozzle boat-tail expansion. Lip shock movement caused a favorable change in the observed pressure signature. These results were applied to a simplified supersonic vehicle geometry with no inlets and no tail, in which the goal was to demonstrate how under-expanded nozzle operation reduced the sonic boom signature by twelve percent. A secondary goal was to demonstrate the use of the Cart3D inviscid code for off-body pressure signatures including the nozzle plume effect.
\end{abstract}

$\mathrm{AOA}=$ Angle of attack, degrees

$\beta=$ Nozzle boat-tail angle, degrees

$\mathrm{D}=$ Test nozzle diameter, in

$\mathrm{h}=$ Distance below vehicle, in

$1=$ Vehicle length, in

$\mathrm{M}_{\infty}=$ Free-stream Mach number

NPR $=$ Nozzle pressure ratio $=\mathrm{P}_{\mathrm{t}} / \mathrm{P}_{\infty}$

$\mathrm{P}=$ Local static pressure, psia

$\mathrm{P}_{\mathrm{t}}=$ Total pressure in nozzle, psia

$\mathrm{P}_{\infty}=$ Free-stream static pressure, psia

$\Delta \mathrm{P}=\mathrm{P}-\mathrm{P}_{\infty}$

$\Delta \mathrm{P} / \mathrm{P}=\left(\mathrm{P}-\mathrm{P}_{\infty}\right) / \mathrm{P}_{\infty}$

$\mathrm{T}_{0}=$ Nozzle total temperature, ${ }^{0} \mathrm{R}$

$\mathrm{T}_{\infty}=$ Free-stream total temperature, ${ }^{0} \mathrm{R}$

$\mathrm{t}=$ Time, seconds

$\mathrm{x}=$ Distance along abscissa of pressure signature, in

$\mathrm{y}=$ Distance from nozzle centerline, in

\section{Introduction}

NASA has been conducting extensive research programs to reduce the sonic boom signature caused by supersonic flight speeds. Current aircraft flight restrictions, allowing supersonic flight over water only, are due to the disturbance caused by the sonic boom. The sonic boom is generated by coalescing shock waves formed by aircraft components, which generate an $\mathrm{N}$-wave. A sample $\mathrm{N}$-wave sonic boom signature is shown in Figure 1. As the aircraft 'bow-wave' passes over an observer, its $\mathrm{N}$-wave consists of a sharp rise in pressure followed by a dramatic reduction in pressure and finally a sudden return to atmospheric pressure. Previous work by NASA, such as the Shaped Sonic Boom Demonstrator ${ }^{1}$ (SSBD) and the Quiet Spike ${ }^{2}$, have studied how aircraft shaping can reduce the sonic boom signature generated by the front of the aircraft.

\footnotetext{
${ }^{1}$ Aerospace Engineer, Inlet and Nozzle Branch, 21000 Brookpark Road, and AIAA Member.
} 
Complementary work is desired to reduce the sonic boom signature in the aft portion of the sonic boom $\mathrm{N}$ wave, which in turn would decrease the peak-to-peak magnitude and result in a reduced sonic boom. This can be accomplished by aircraft shaping and through study of how aft components, such as the tail, nacelles, and nozzles contribute to the right hand portion of the sonic boom N-wave. The presented work studies the effects of the nozzle exhaust plume and the contribution to the right hand portion of the sonic boom $\mathrm{N}$-wave.

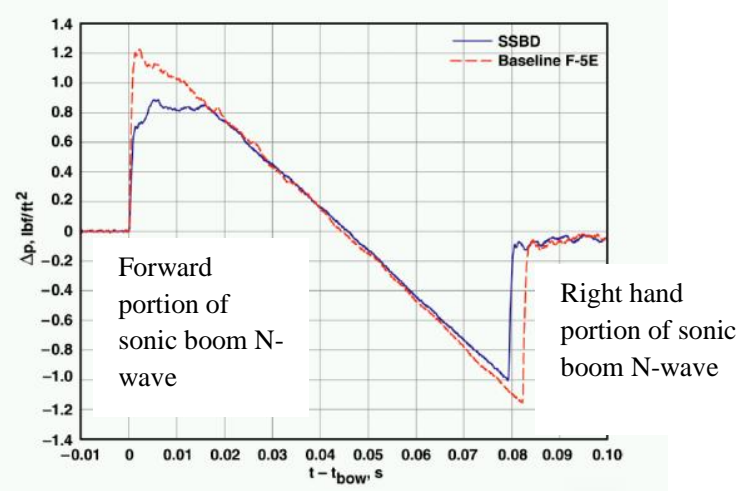

Figure 1. Ground-level shaped sonic boom recording in blue, baseline F-5E N-Wave in red, SSBD flight $9^{1}$

Previous work on exhaust nozzles was reported by Putnam and Capone ${ }^{3}$ and by Barger and Melson ${ }^{4}$. In the work by Putnam and Capone, a variety of nozzles were tested from fully expanded Mach 1.7 nozzle exit conditions to fully expanded Mach 2.9 nozzle exit conditions. Their study was conducted in a wind tunnel, where near-field pressure measurements were made at one nozzle diameter away from the model. Wind tunnel conditions were Mach 2.2 at a simulated altitude of 50,000 feet. In 2009, Castner ${ }^{5}$ revisited this work to use as a baseline for studies on the exhaust nozzle contribution to sonic boom. Near-field pressure signatures from the wind tunnel test were examined, in which stronger pressure signatures were observed for high levels of nozzle pressure ratio. From the Putnam and Capone report, a baseline nozzle was selected for a two dimensional Computational Fluid Dynamics (CFD) study. During the CFD analysis, it was determined that over-expanded and under-expanded operation of the nozzle had an effect on the $\mathrm{N}$-wave boom signature. The work demonstrated the feasibility of reducing the magnitude of the sonic boom N-wave by controlling the nozzle plume interaction with the nozzle boat-tail flow structure. Under-expanded exhaust nozzle flow had a favorable result on near field pressure signatures, suggesting that the nozzle plume shock location could be controlled through control of nozzle pressure or nozzle divergent section geometry. This work was confirmed by Bui ${ }^{6}$ for much higher pressure ratios.

The effects of the exhaust plume need to be integrated onto a supersonic vehicle in order to validate the effect on overall sonic boom signature. The goal was to demonstrate the exhaust nozzle plume effect on off-body pressure signatures for a simplified 'single engine' wing-body model. A secondary goal was to demonstrate the use of the Cart3D inviscid code for off-body pressure signatures including the nozzle plume effect; as use of Cart3D had clear benefits of reduced computing time. Evaluation of a simplified vehicle was selected to perform a building block approach: first, exhaust plume effects could be observed without the inlets or the tail; later, the inlets and tail could be included in higher complexity analyses. To perform this simplified study, the $59^{\circ}$ delta wing-body model was selected from Hunton ${ }^{7}$. The vehicle was analyzed to determine the effects of an exhaust nozzle plume on the overall vehicle pressure signature, and thereby the sonic boom signature. Two CFD codes were used for this analysis, Wind-US and Cart3D. Cart3D had been validated by Wintzer ${ }^{8}$ for sonic boom analysis on supersonic vehicle shapes, but not including the nozzle plume effect. Wind-US had been extensively validated for use in exhaust nozzle analysis. Results are presented for the vehicle at Mach 1.68 and Mach 2.2 to evaluate the effects of the nozzle exhaust. Comparisons are made between the viscous Wind-US solutions and the inviscid Cart3D solutions. Cart3D solutions include solid body representations of the nozzle plume, allowing inviscid analysis of plume effects. 


\section{Discussion of Previous Result}

Figure 2 depicts the design of the Mach 2.0 baseline supersonic exhaust nozzle configuration, which was a replica of the Putnam 'Nozzle 6.' Previous computational and wind tunnel tests were performed on this nozzle for a flight speed of Mach 2.2 and an altitude of 50,000 feet.

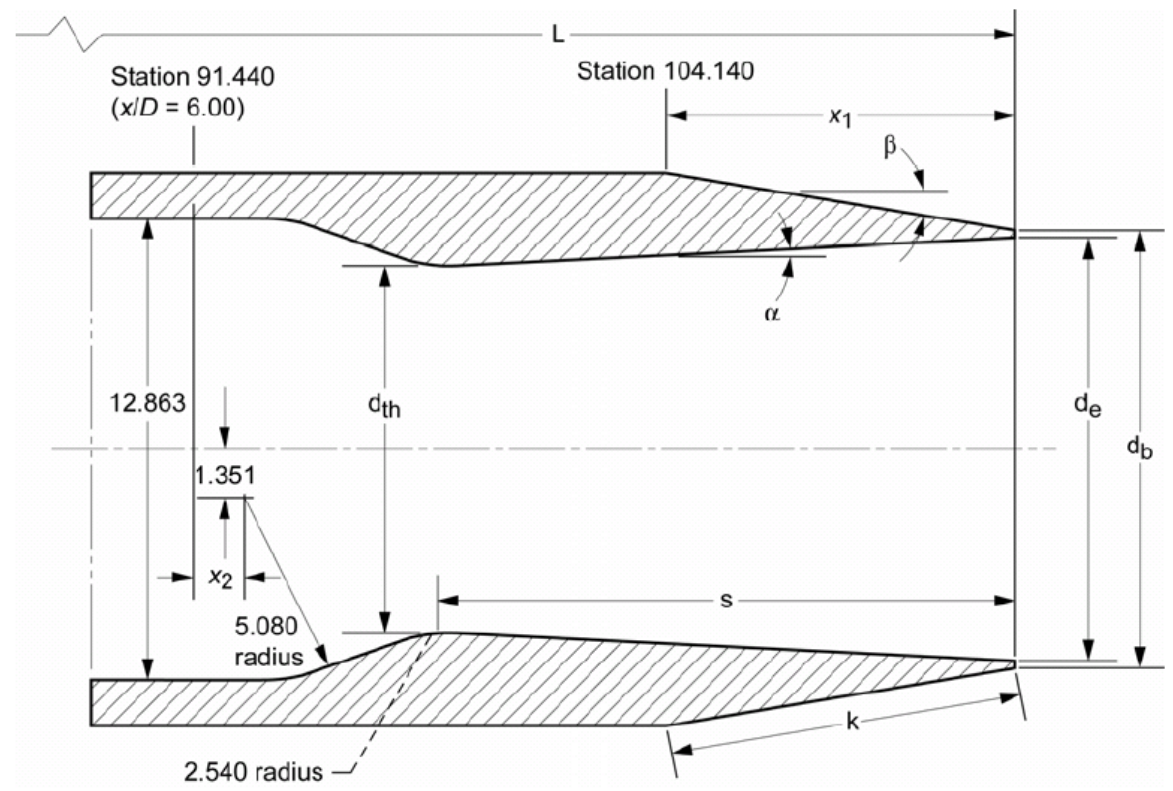

\begin{tabular}{|c|c|c|c|c|c|c|c|c|c|c|c|c|c|c|c|}
\hline Nozzle & $M_{j, \text { des }}$ & $\left(P_{t, j} / P_{\infty}\right)_{\text {des }}$ & $\begin{array}{c}\alpha, \\
\mathrm{deg}\end{array}$ & $\begin{array}{c}\beta, \\
\mathrm{deg}\end{array}$ & $x_{1}$ & $L$ & $k$ & $s$ & $d_{\text {th }}$ & $d_{e}$ & $d_{b}$ & $A_{\text {th }}$ & $A_{e}$ & $A_{e} / A_{\text {th }}$ & $x_{2}$ \\
\hline 1 & 2.920 & 32.58 & 11.50 & 0 & 15.240 & 119.380 & 15.240 & 18.519 & 7.577 & 15.011 & 15.240 & 45.09 & 176.98 & 3.925 & 2.908 \\
\hline 2 & 2.272 & 11.97 & 7.28 & 0 & 15.240 & 119.380 & 15.240 & 18.747 & 10.264 & 15.011 & 15.240 & 82.75 & 176.98 & 2.139 & 4.224 \\
\hline 3 & 2.740 & 24.77 & 11.50 & 0 & 12.192 & 116.332 & 12.192 & 16.878 & 8.255 & 15.011 & 15.240 & 53.52 & 176.98 & 3.307 & 2.118 \\
\hline 4 & 2.523 & 17.72 & 11.50 & 0 & 9.144 & 113.284 & 9.144 & 14.883 & 9.144 & 15.011 & 15.240 & 65.66 & 176.98 & 2.695 & 2.118 \\
\hline 5 & 2.267 & 11.88 & 9.06 & 0 & 9.144 & 113.284 & 9.144 & 15.011 & 10.288 & 15.011 & 15.240 & 83.12 & 176.98 & 2.129 & 1.953 \\
\hline 6 & 2.024 & 8.12 & 6.04 & 5 & 9.109 & 113.249 & 9.144 & 15.105 & 10.223 & 13.417 & 13.646 & 82.08 & 141.39 & 1.722 & 1.778 \\
\hline 7 & 1.700 & 4.94 & 3.04 & 10 & 8.999 & 113.139 & 9.144 & 15.166 & 10.231 & 11.836 & 12.065 & 82.21 & 110.03 & 1.338 & 1.580 \\
\hline
\end{tabular}

Figure 2. Baseline Nozzle, from Putnam ${ }^{3}$.

While a nozzle pressure ratio (NPR) of 8 produced fully expanded flow, simulations were also conducted at NPRs of six and seven, resulting in over-expanded nozzle flow, and at NPRs of nine and 10, resulting in underexpanded nozzle flow. The effects of under-expanded and over-expanded nozzle flow were computed at a distance far from the nozzle, at 10 nozzle exit diameters. Changes in NPR caused changes in the magnitude of the observed pressure signature, and are shown in Figure 3.a. Figure 3.b. shows what happens to the pressure signatures when they were propagated to the ground. It was evident that as NPR was increased, the peak-to-peak magnitude for the right hand portion of the sonic boom signature was reduced. The conclusion was that under-expanded nozzle flow had a favorable effect on sonic boom signature $\left(\right.$ Castner $\left.^{5}\right)$. 


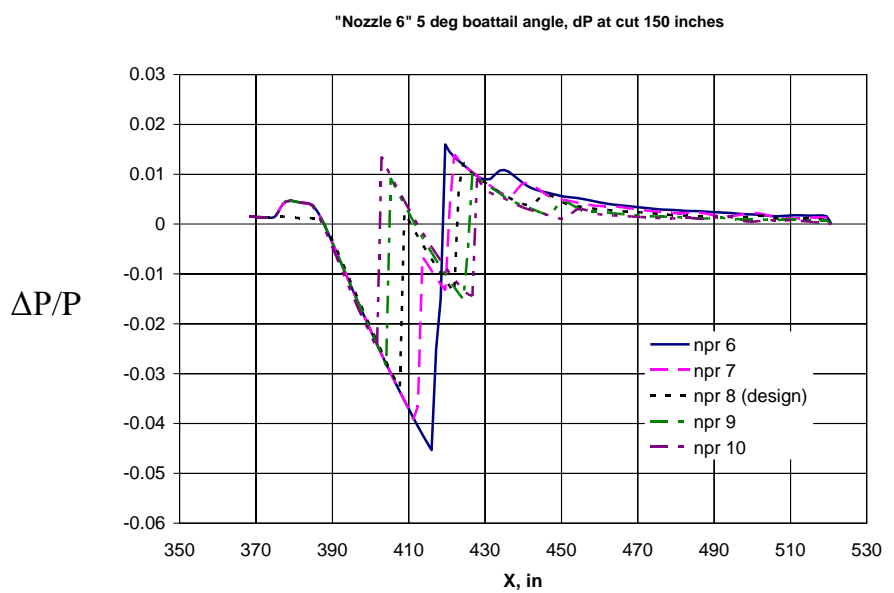

Figure 3.a. Far-field pressure profiles $\Delta P / P$ at $y=150$ in from nozzle centerline.

Baseline 'Nozzle 6' NPR 6 to 10.

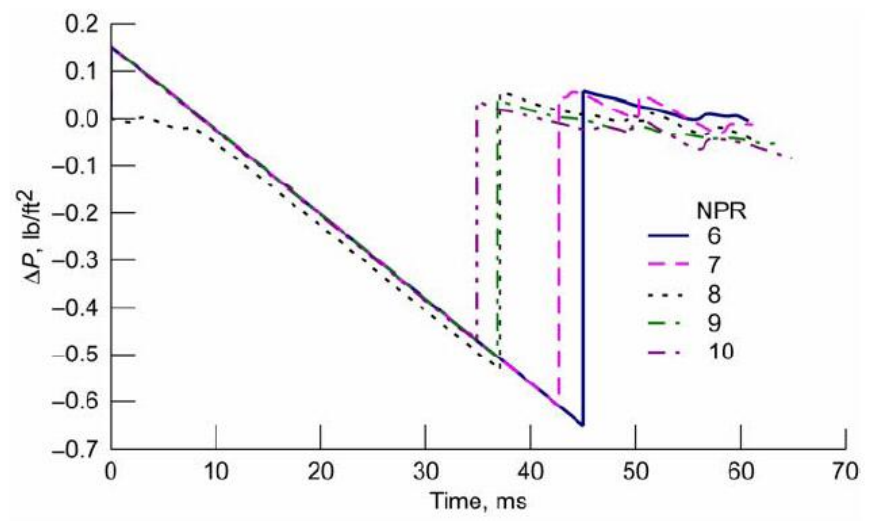

Figure 3.b. Estimated sonic boom signature at ground through an ideal atmosphere, NPR 6 to 10.

\section{Problem and Geometry Modeling}

It was desired to integrate nozzle plume effects onto a simplified supersonic vehicle to demonstrate plume effects in a realistic environmnet. A simplified aircraft geometry was available from Hunton ${ }^{7}$. This configuration was the $59^{\circ}$ delta wing-body, shown in Fig. 4.a. This configuration possessed a simplified baseline supersonic wing geometry, given in Fig. 4.b. The supersonic vehicle geometry was paired with the baseline 'Nozzle 6' geometry for a study on reducing the expansion wave from a vehicle, similar to reducing the boat-tail expansion on an isolated nozzle. In this case, the $59^{\circ}$ delta wing-body model diameter was scaled up from a 0.54 inch radius to match the 7.625 inch nozzle outer radius. Flow conditions for 'Nozzle 6' are outlined in Table 1, and were run at Mach 2.2 conditions at an angle of attack of zero.

Table 1. Flow Conditions

\begin{tabular}{cccc}
\hline \multicolumn{4}{c}{ Table 1. Flow Conditions } \\
\hline \multicolumn{2}{c}{ Nozzle Stream } & \multicolumn{2}{c}{ Free-stream } \\
$\mathrm{T}_{\mathrm{o}}{ }^{\circ} \mathrm{R}$ & 530 & $\mathrm{~T}_{\infty}{ }^{\circ} \mathrm{R}$ & 530 \\
$\mathrm{NPR}$ & 18 & $\mathrm{P}_{\infty}$ & 1.68 \\
& & $\mathrm{M}_{\infty}$ & 2.2 \\
& & $\mathrm{AOA}$ & $0^{\circ}$ \\
\hline
\end{tabular}




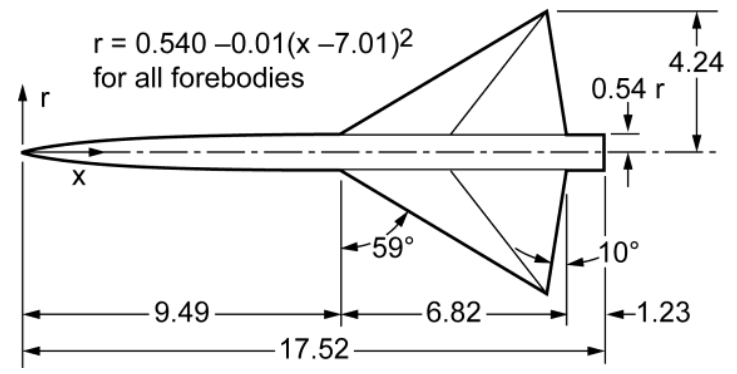

Figure 4.a. $59^{\circ}$ delta wing-body model.

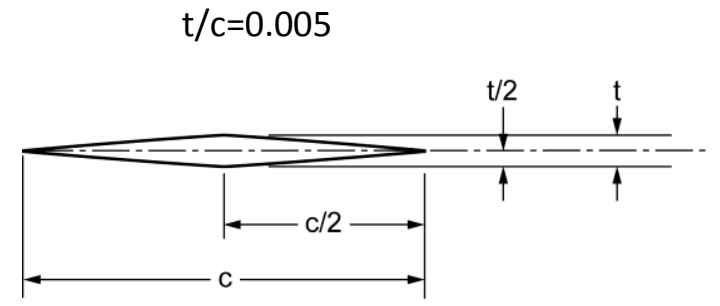

Figure 4.b. Wing cross section.

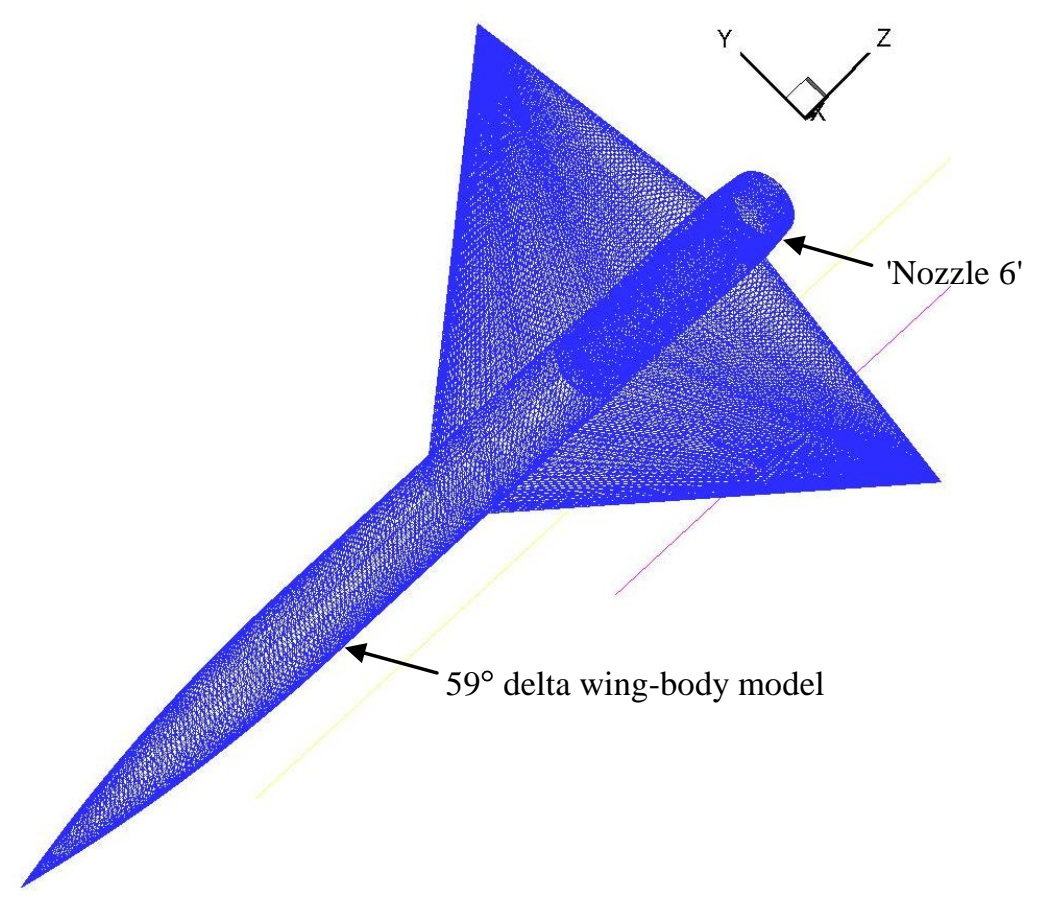

Figure 4.c. $59^{\circ}$ integrated delta wing-body model with 'Nozzle 6.'

\section{Computational Modeling}

\section{IV.a. Modeling with Wind-US}

\section{IV.a.1. Wind-US Description}

Wind-US is a general purpose fluid flow solver that is used to numerically solve various sets of equations governing physical phenomena ${ }^{9}$. Wind-US was used to take advantage of the established capability to correctly compute nozzle plumes with viscous and turbulence effects. The code supports the solution of the Euler and NavierStokes equations of fluid mechanics, along with supporting equation sets governing turbulent and chemically 
reacting flows. The version used was Wind-US 2.0. Wind-US was used with the modified second order Roe upwind scheme for stretched grids, implicit time stepping with a CFL number of 1.0, and the SST turbulence model.

IV.a.2. Wind-US Modeling for $\mathrm{NPR}=0$ at $\mathrm{M}_{\infty}=1.68$ and $\mathrm{M}_{\infty}=2.2$

The computational domain was a structured grid which consisted of 25 zones, and 11,072,000 grid points, and is shown in Figure 5.a. Zones were aligned with shock waves from the vehicle. The domain extended from 0.2 vehicle lengths upstream of the vehicle, 1.0 vehicle lengths downstream, and 3.1 vehicle lengths in radius.

Symmetry was used for the vertical and horizontal vehicle axis, so only $1 / 4$ of the vehicle was modeled, see Figure 5.b. Multiblock wall-packed grids were generated for use on parallel processor systems. Viscous wall boundaries were used for all vehicle surfaces. Convergence was monitored by monitoring changes in the off-body pressure signature at $\mathrm{h} / \mathrm{l}$ of 3.0. Cases were run on a local computer cluster with 12 processors and took approximately 15 to 20 days to converge.

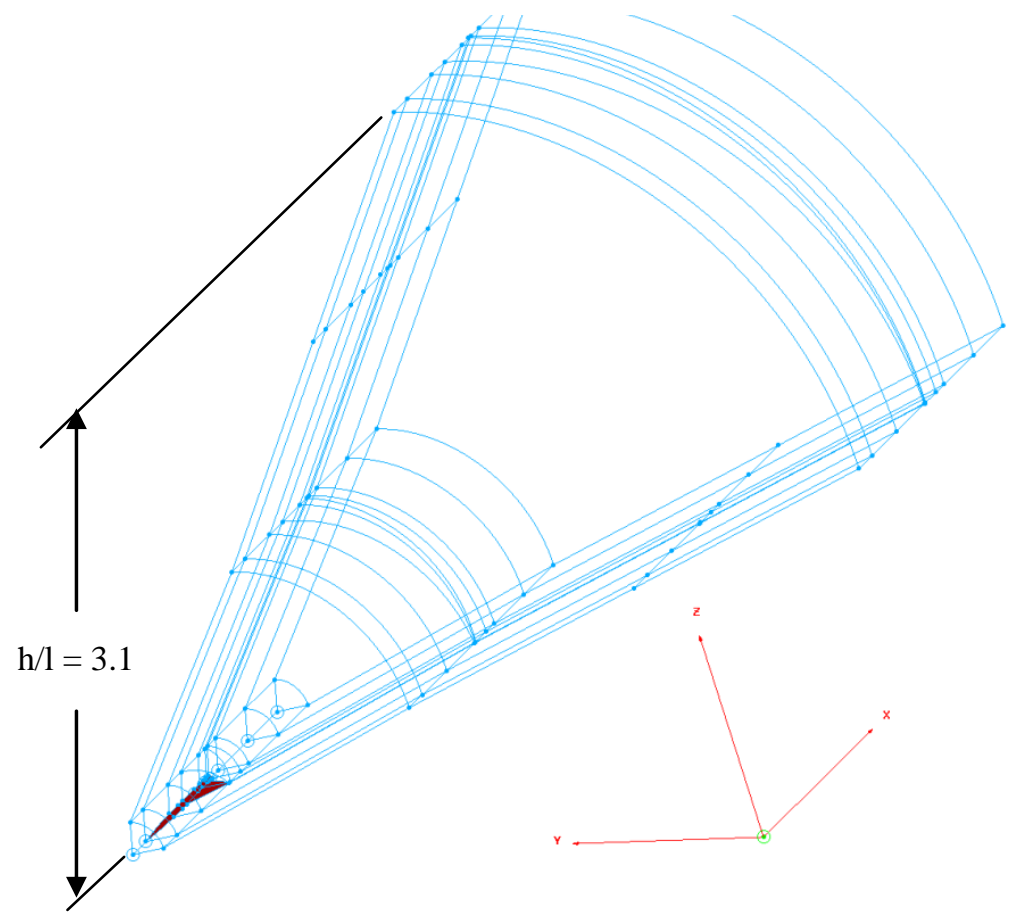

Figure 5.a. Wind-US computational domain. 


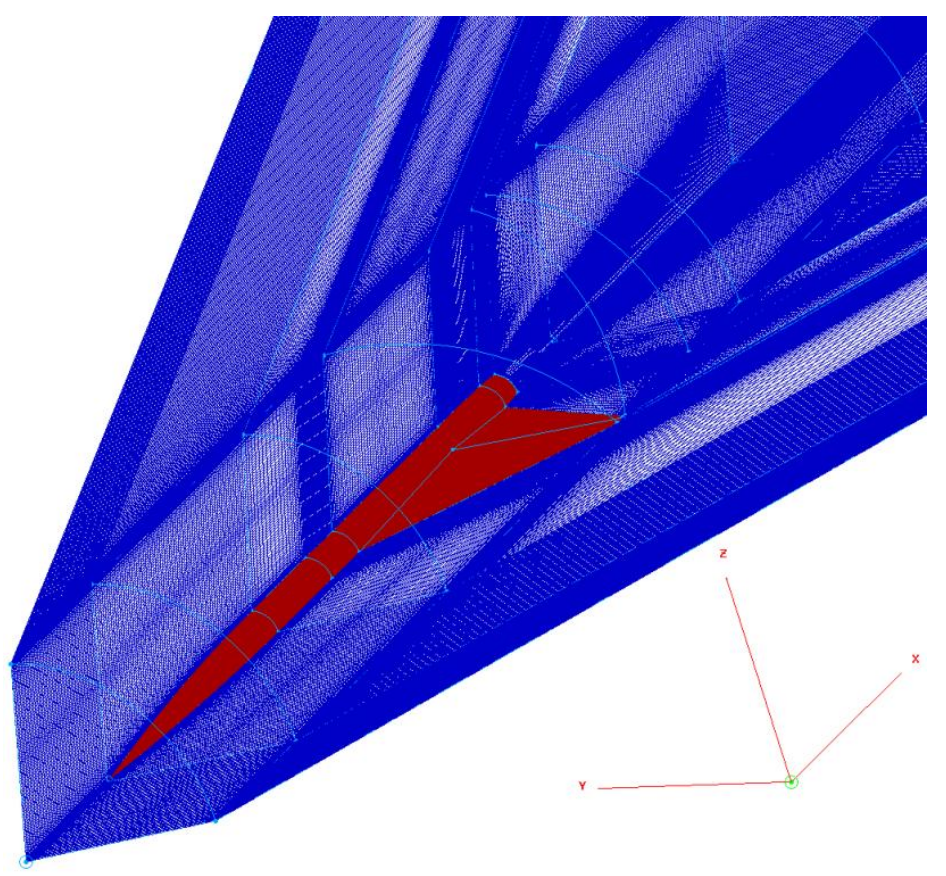

Figure 5.b. Wind-US grid of the wing-body vehicle.

\section{IV.a.3. Wind-US Modeling for NPR=18 at $\mathrm{M}_{\infty}=2.2$}

The computational domain was identical to the baseline vehicle with no nozzle flow, but with the addition of the internal nozzle contour for 'Nozzle 6' and a block upstream of the nozzle inlet to establish nozzle inlet flow conditions. The computational domain consisted of 27 zones, and 11,716,000 grid points. The simulation was run at Mach 2.2 free-stream conditions, with a nozzle presssure ratio of 18. This high NPR was selected based on previous slot-nozzle and wing research by Castner ${ }^{10}$, indicating that under-expanded nozzle flow improved the sonic boom signature.

\section{IV.b. Modeling with Cart3D}

\section{IV.b.1 Cart3D Description}

Cart3D is a high-fidelity inviscid analysis package for conceptual and preliminary aerodynamic design. It allows users to perform automated CFD analysis on complex geometry. Geometry for Cart3D is in the form of surface triangulations. These may be generated from within a Computer-Aided Design (CAD) package, from legacy surface triangulations or from structured surface grids. Cart3D uses adaptively refined Cartesian grids to discretize the space surrounding a geometry and cuts the geometry out of the set of "cut-cells" which intersect the surface triangulation. The flow solver is parallel and can take full advantage of multi-core and multi-cpu hardware. Solutions used the Cart3D Adjoint Adaptation module. This module uses adjoint-weighted residual error-estimates to drive mesh adaptation. Once a user specifies outputs of interest, (lift, drag, etc.) with a corresponding error tolerance, this module automatically meshes the simulation to drive the remaining numerical errors in the outputs below the requested tolerance. This module has been validated for sonic boom prediction by Wintzer ${ }^{8}$, and this capability was the reason Cart3D was selected for analysis of this problem. The adaptation module allows greatly reduced time spent on mesh generation and analysis. 
The model was run on the Pleiades computer cluster at the NASA Ames Research Center. The adjoint adaptation module uses Open MultiProcessing (OpenMP) for code parallelization within a node, and at the time of writing, could not utilize message passing interface (MPI) to work between nodes, required on Peliades architecture. As a result, a single node with 12 processors was used until the node ran out of memory, at approximately 4.5 million cells.

IV.b.2. Modeling with Cart3D for $\mathrm{NPR}=0$ at $\mathrm{M}_{\infty}=1.68$ and $\mathrm{M}_{\infty}=2.2$

The Cart3D surface grid was also developed from the baseline 'Nozzle 6 ' paired with the $59^{\circ}$ delta-wing body model. The computational domain extended 10 vehicle lengths in all directions, and an adaptation line sensor at three vehicle lengths below the vehicle was used to drive the mesh adaptation. The mesh was rotated to align with vehicle Mach angle.

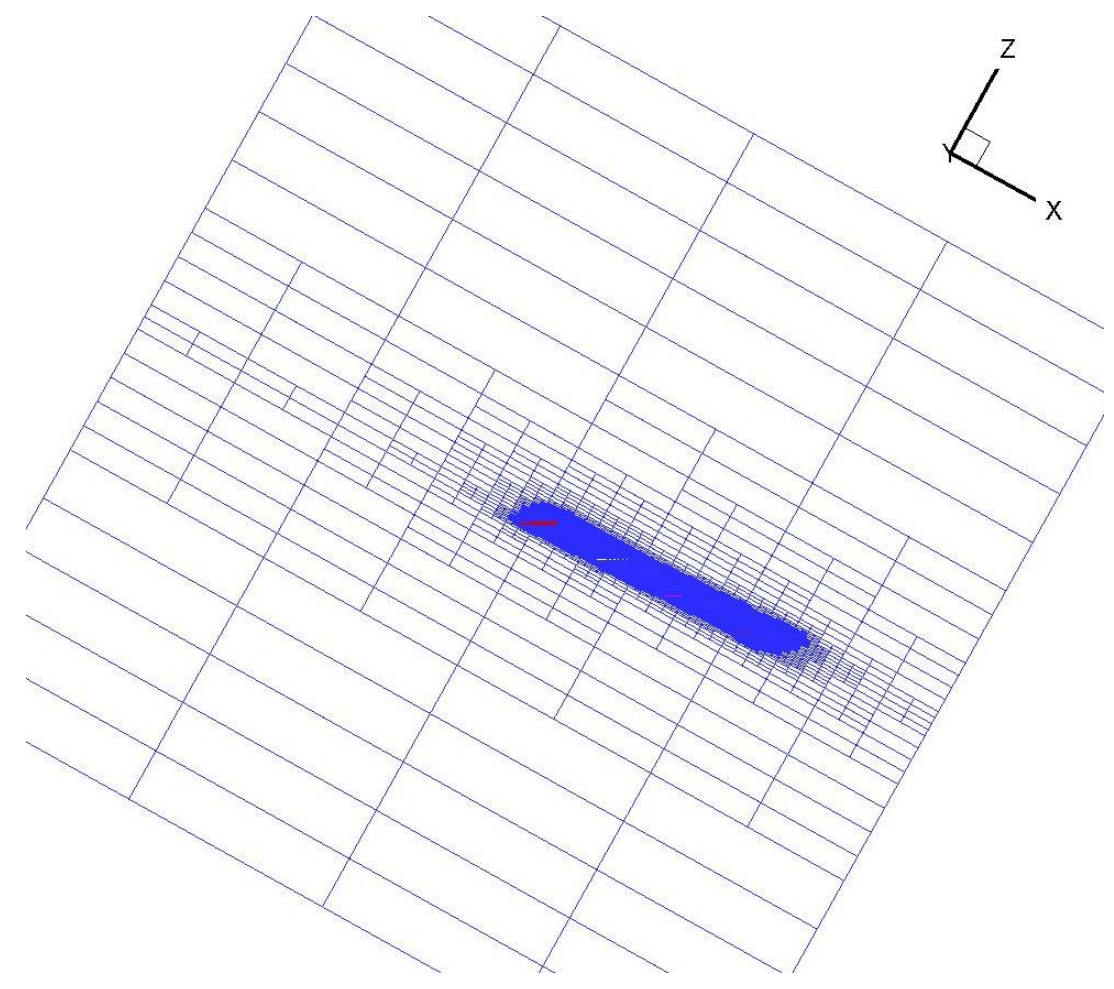

Figure 6.a. Cart3D computational domain. 


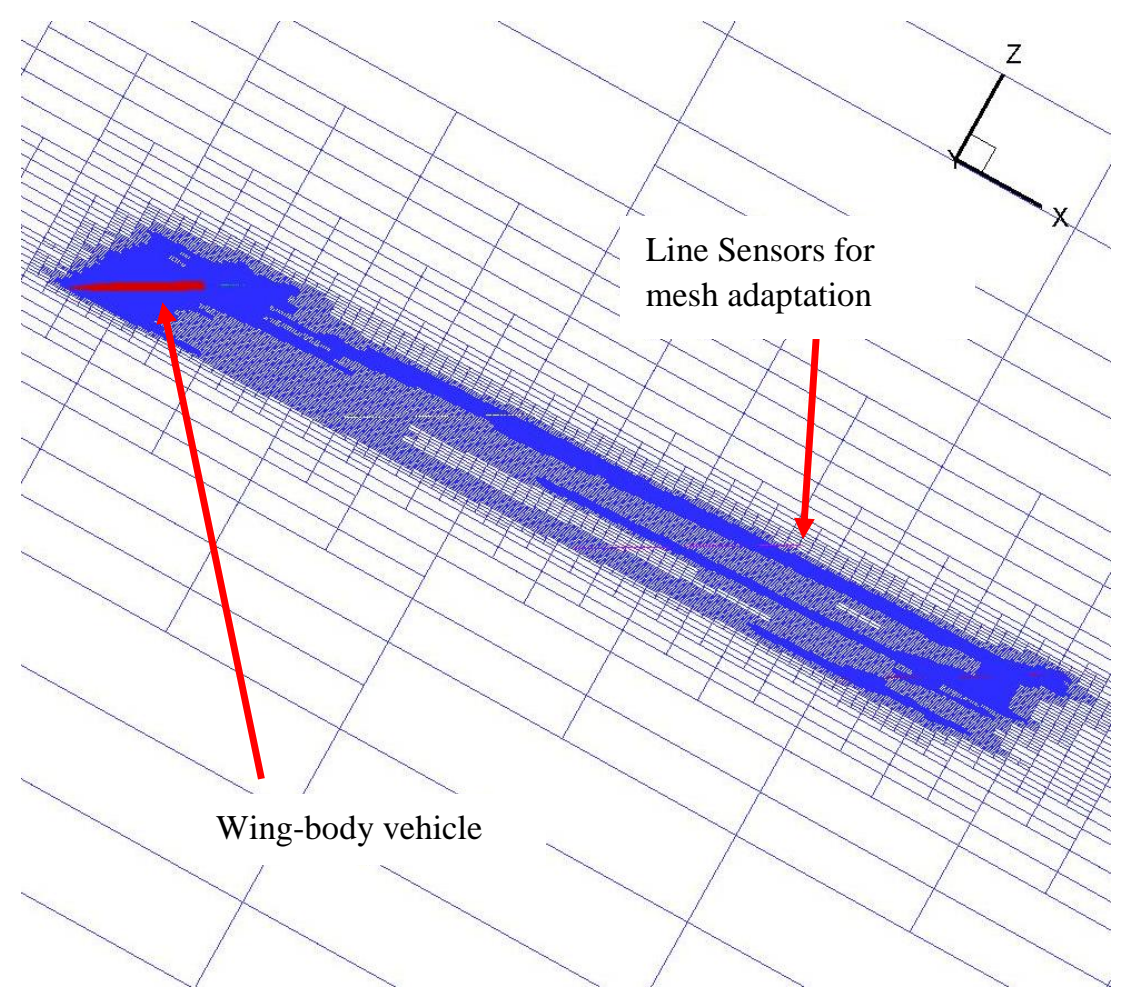

Figure 6.b. Cart3D cells generated through mesh adaptation.

IV.b.3. Modeling with Cart3D for NPR=18 at $\mathrm{M}_{\infty}=2.2$

The Cart3D surface grid was again developed from the baseline 'Nozzle $6^{\prime}$ paired with the $59^{\circ}$ delta-wing body model. Two cases were run. One case with a pressure boundary at the nozzle plenum, to let Cart3D compute the nozzle plume, and a second case with a solid plume. Based on the work by Putnam and Capone, nozzle exhaust plumes could be modeled as solid bodies. A plume shape was developed for a nozzle pressure ratio of 18 , based on a two dimensional Wind-US simulation, and was attached to the nozzle. The computational domain extended 10 vehicle lengths in all directions, and a line sensor at three vehicle lengths below the vehicle was used to drive the mesh adaptation.

\section{IV.c. PCBoom}

Environmental analysis of supersonic aircraft operations requires calculation of sonic boom amplitudes. A number of computer models have been developed, each appropriate for various purposes. The models in common use for boom assessment are: (1)PCBoom - single event, arbitrary maneuver, full ray tracing model, including focused "superboom" analysis. (2) CABoom - simplified boom prediction for steady flight in the standard atmosphere, based on the method of H.W. Carlson. (3) BooMap - cumulative sonic boom exposure under supersonic air combat training arenas, based on long term measurements in a number of airspaces. These models have been in use for some time, and are widely accepted. All were written for operation on a PC under MS-DOS ${ }^{11}$. For this work, modules of PCBoom were used to extrapolate wing-body vehicle pressures to an estimated sonic boom signature directly under the vehicle, for straight and level flight at Mach 2.2 and 50,000 ft altitude. These calculations were done to compare results with and without an exhaust nozzle plume. 


\section{Results}

Results are presented for the three cases: (1) Baseline vehicle, Mach 1.68, no nozzle flow, (2) Baseline vehicle, Mach 2.2, no nozzle flow, (3) Baseline vehicle, Mach 2.2, nozzle with nozzle pressure ratio of 18.

V.a. Results for $\mathrm{NPR}=0$ at $\mathrm{M}_{\infty}=1.68$

Recall, the goal was to demonstrate the exhaust nozzle plume effect on off-body pressure signatures for a simplified 'single engine' wing-body model. A secondary goal was to demonstrate the use of the Cart3D inviscid code for off-body pressure signatures including the nozzle plume effect; as use of Cart3D had clear benefits of reducing computing time when compared to a Wind-US viscous solution.

Off-body pressure signatures at $\mathrm{h} / \mathrm{l}$ of 3.6 were reported by Hunton ${ }^{7}$, who performed both a theoretical and experimental analysis on the basic $59^{\circ}$ wing body model at Mach 1.68. The plot in Figure 7 shows the location and strength for the nose shock, wing shock and the aft shock, at $h / 1$ of 3.6. The first peak at $x / l=0$ was the nose shock, with a $\Delta \mathrm{P} / \mathrm{P}=0.01$; the second peak at $\mathrm{x} / \mathrm{l}=0.5$ was generated by the wing leading edge, with a $\Delta \mathrm{P} / \mathrm{P}=0.018$; and finally the third valley at $\mathrm{x} / \mathrm{l}=1.0$ was generated by the vehicle expansion and closeout shock back to free-stream conditions with a $\Delta \mathrm{P} / \mathrm{P}=-0.023$.

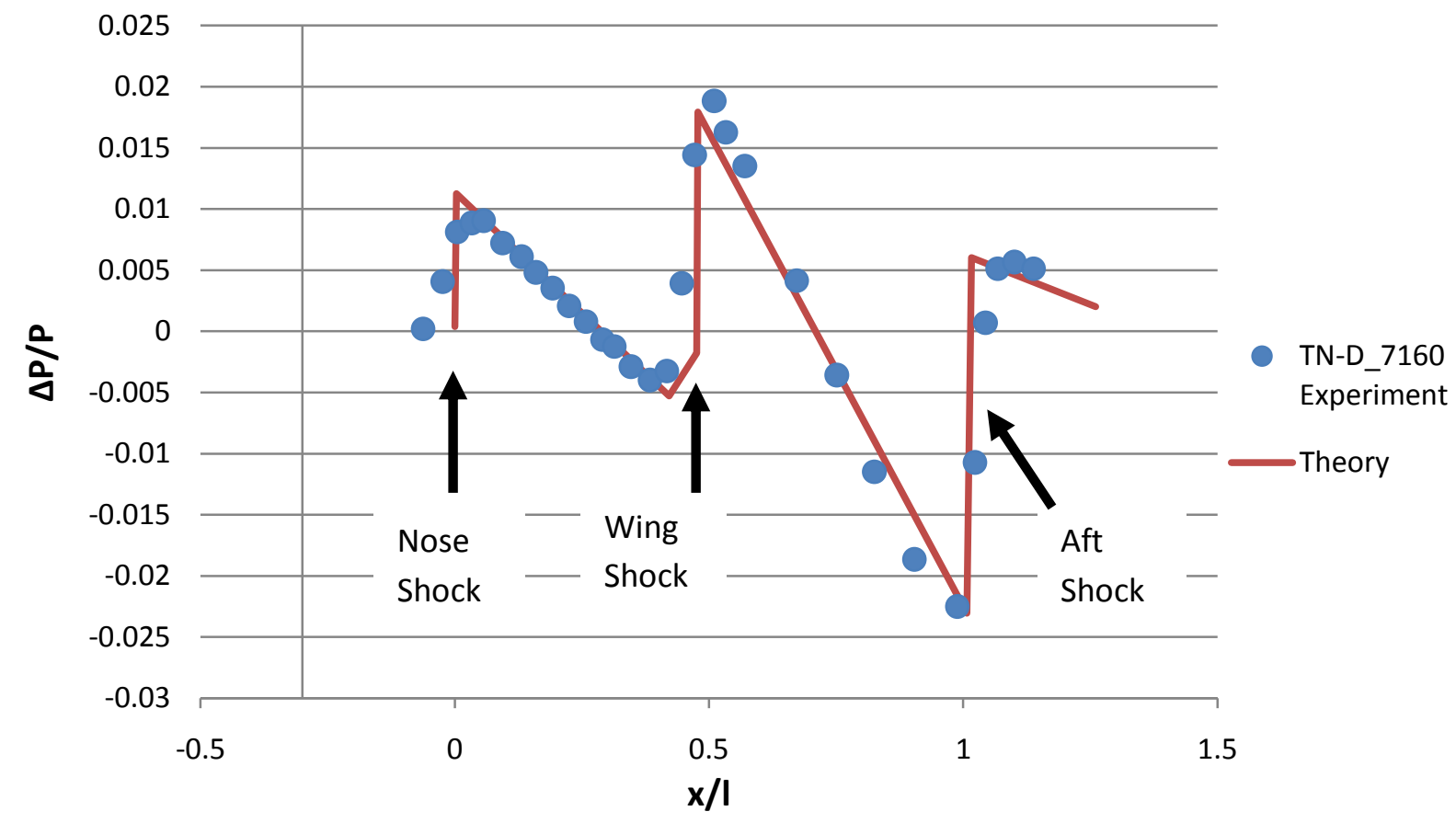

Figure 7. Theoretical and experimental data, $\mathrm{h} / \mathrm{l}=3.6\left(\right.$ Hunton $\left.^{7}\right)$

For comparison, Figure 8 shows the Wind-US viscous solution for the $59^{\circ}$ wing-body model with 'Nozzle 6 ' geometry and NPR $=0$. Recall, this case was generated to demonstrate the effect of the exhaust nozzle plume, and was run to an $\mathrm{h} / \mathrm{l}=3.0$ (not 3.6) to save about 30 to 50 percent in computational resources and turnaround time. Wind-US results show the nose shock with a $\Delta \mathrm{P} / \mathrm{P}=0.01$, the wing shock with a maximum $\Delta \mathrm{P} / \mathrm{P}=0.016$, and the vehicle expansion and closeout shock back to free-stream conditions with a $\Delta \mathrm{P} / \mathrm{P}=-0.032$. The overall shape and location of these shocks compared well to Hunton ${ }^{7}$, with the largest difference in the aft portion of this signature. 
Differences were due to two issues: (1) extra expansion around the 'Nozzle 6' boat-tail geometry, and (2) the lack of a model support sting, which was included in the Hunton experiment.

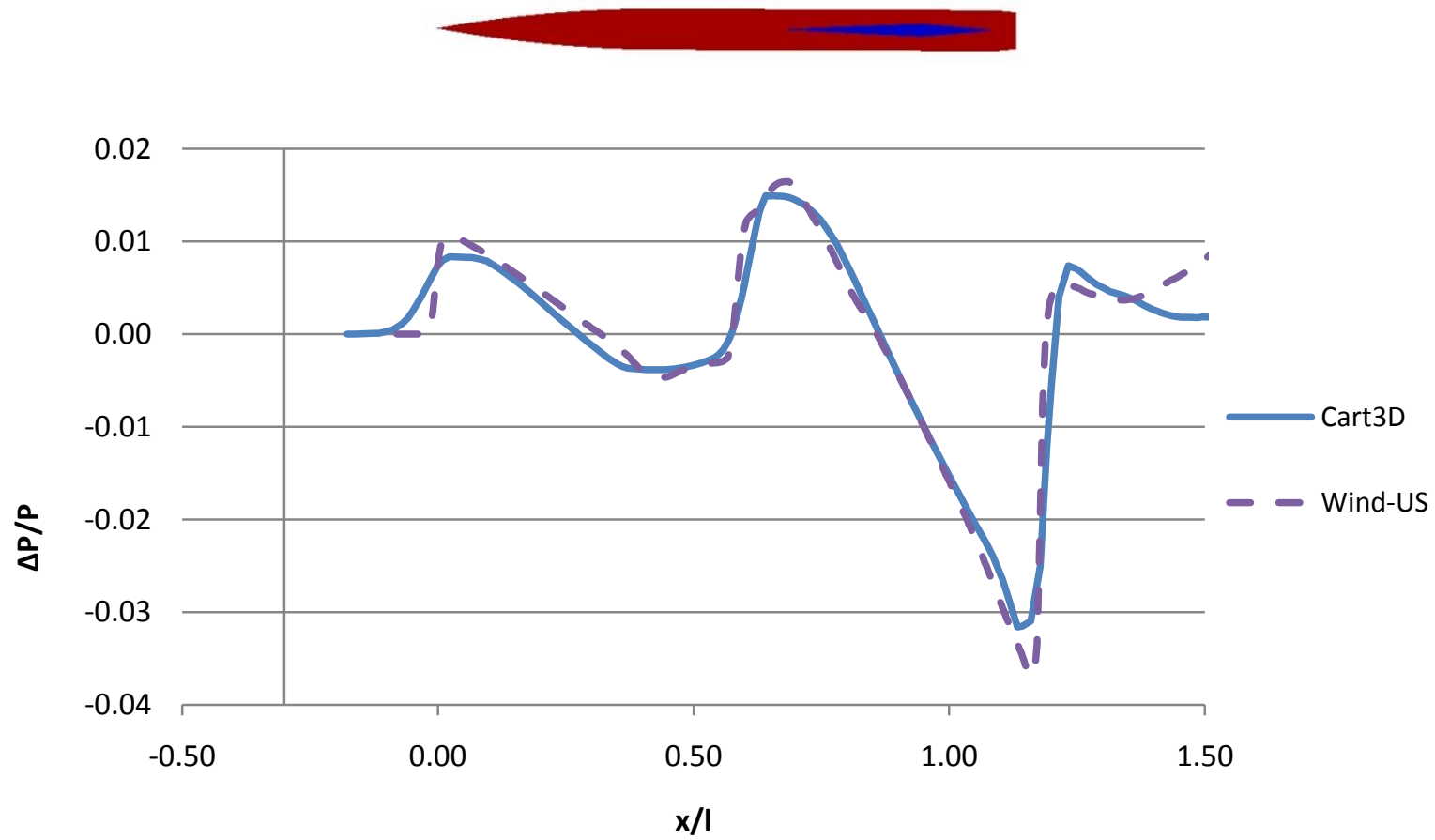

Figure 8. Wind-US vs. Cart3D for Mach 1.68, h/l = 3.0

Inviscid Cart3D results are also plotted in Figure 8. The Cart3D solution captures the same trends as the Wind-US solution. However, Cart3D under-predicts the first and last peaks by $20 \%$ and $12 \%$ respectively.

Furthermore, Cart3D's prediction of the first shock was not as sharp as the Wind-US prediction. These results were obtained with a computational mesh density of approximately 4.5 million grid points. Based on previous reports which included grid studies (Castner ${ }^{5}$ ), a mesh with great density resolved the peaks with more accuracy. For this study, the intent was to compare a configuration with exhaust nozzle plume flow, and without exhaust nozzle plume flow. Care was taken to obtain consistency across all simulations, with mesh densities near 4.5 million grid points for valid comparisons between configurations in this report.

V.b. Results for $\mathrm{NPR}=0$ at $\mathrm{M}_{\infty}=2.2$

Results are presented for Mach 2.2 free-stream flow and no nozzle flow, or "nozzle off" conditions. Figure 9 is a plot of Mach number contours along the vertical and horizontal stream-wise center-planes. The solution displays the shock and expansion from the nosecone, followed by the shock and expansion from the wing. A separation region occurs behind the nozzle, with no exhaust flow, resulting in a strong expansion and shock around the aft separation region. 


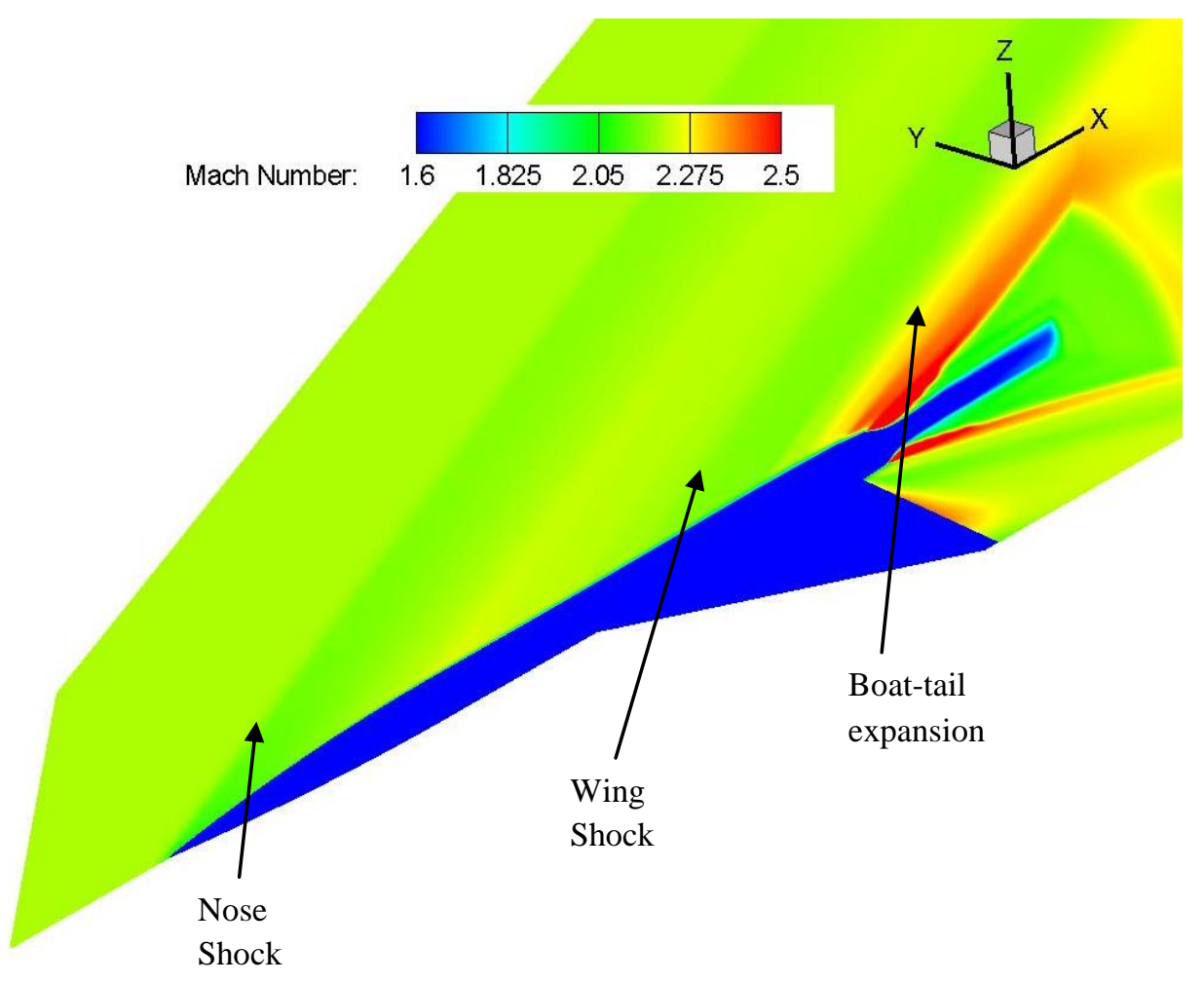

Figure 9a. Wind-US Mach number contours near vehicle (nozzle off, Mach 2.2)

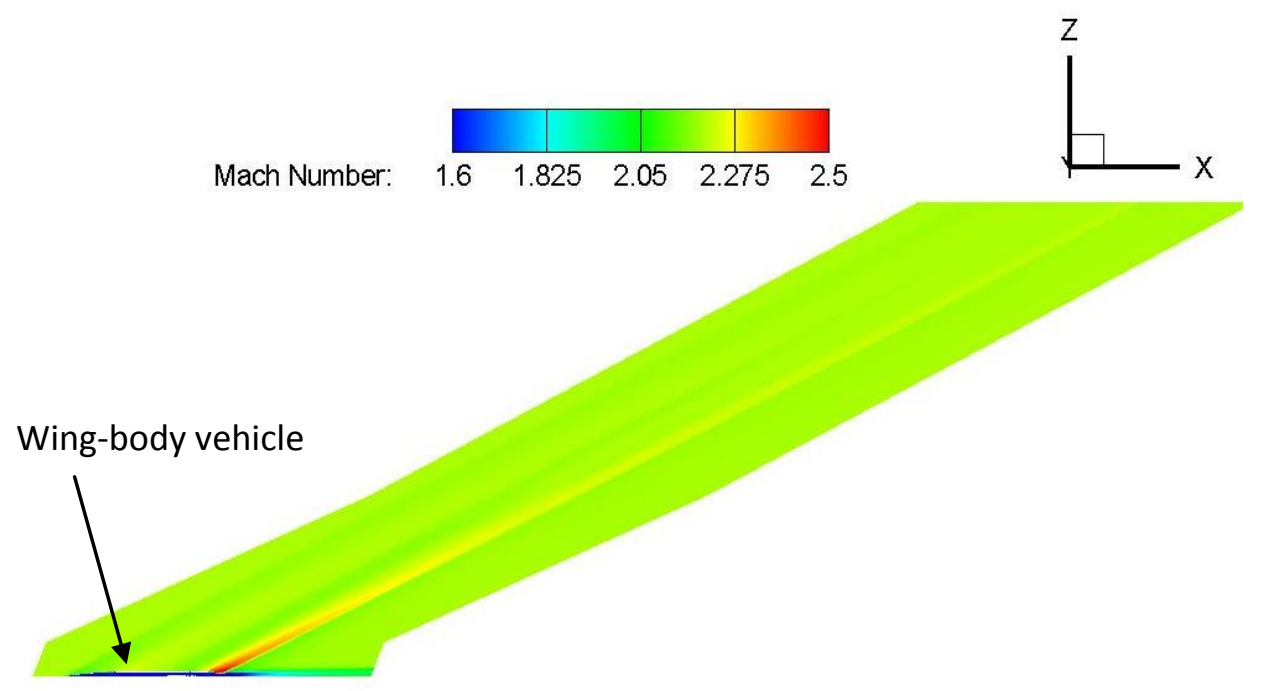

Figure 9b. Wind-US Mach number contours (nozzle off, Mach 2.2) 
Similar flow features can be seen in the Cart3D solution, shown in Figure 10. The separation behind the vehicle is less resolved due to reduced grid density direcly aft of the nozzle.

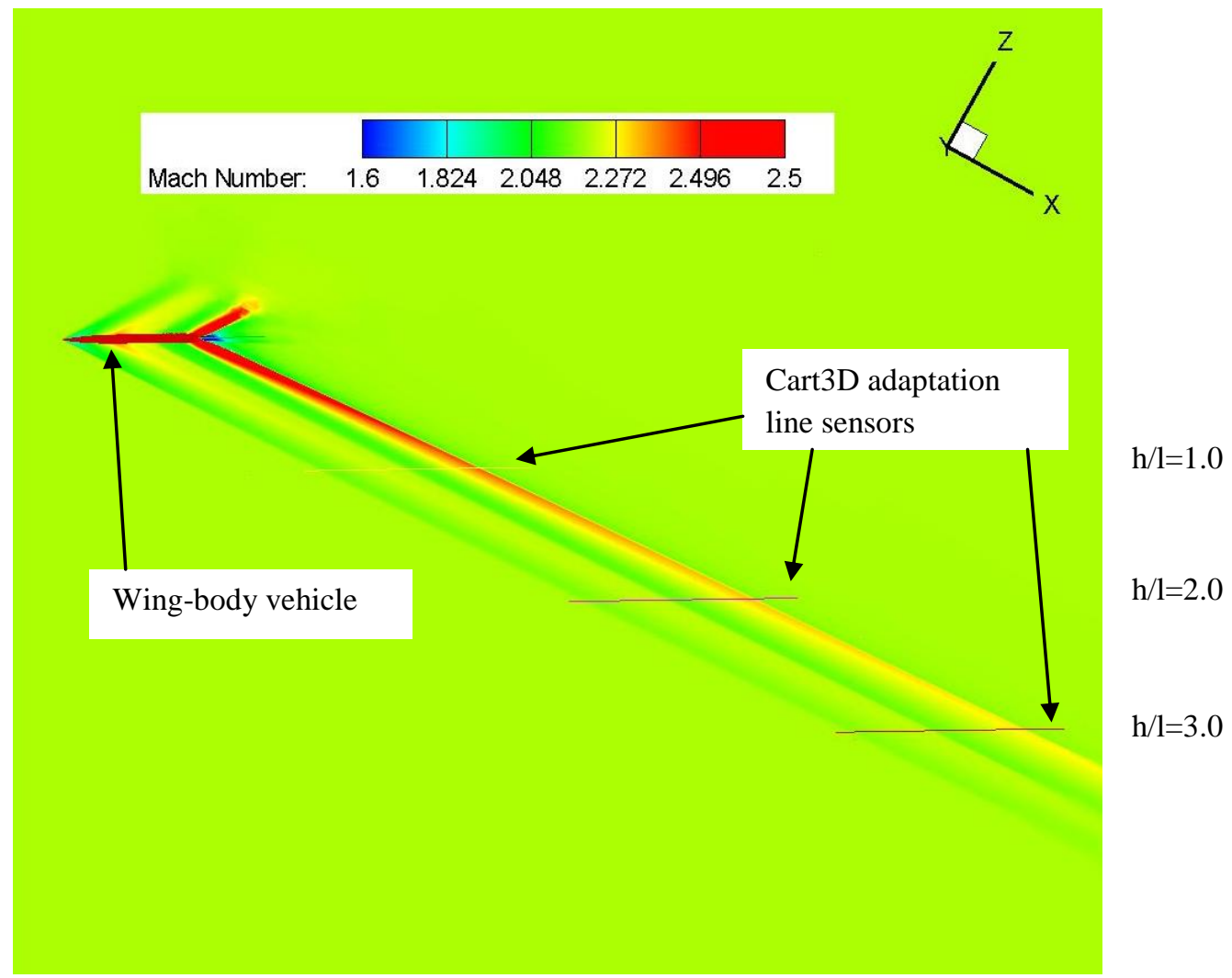

Figure 10. Cart3D Mach number contours for nozzle off, Mach 2.2

The pressure signature at $\mathrm{h} / \mathrm{l}=3$ is displayed in Figure 11. This far field pressure signature demonstrates the shock and expansion from the nosecone, the wing, and the separation behind the nozzle. Again, agreement between the Wind-US solution and the Cart3D solution is good, with the most error occurring again at the nose shock. These results demonstrate that both Wind-US and Cart3D predict the pressure signature at $\mathrm{h} / \mathrm{l}=3$, and provide a baseline signature to compare nozzle plume effects. 


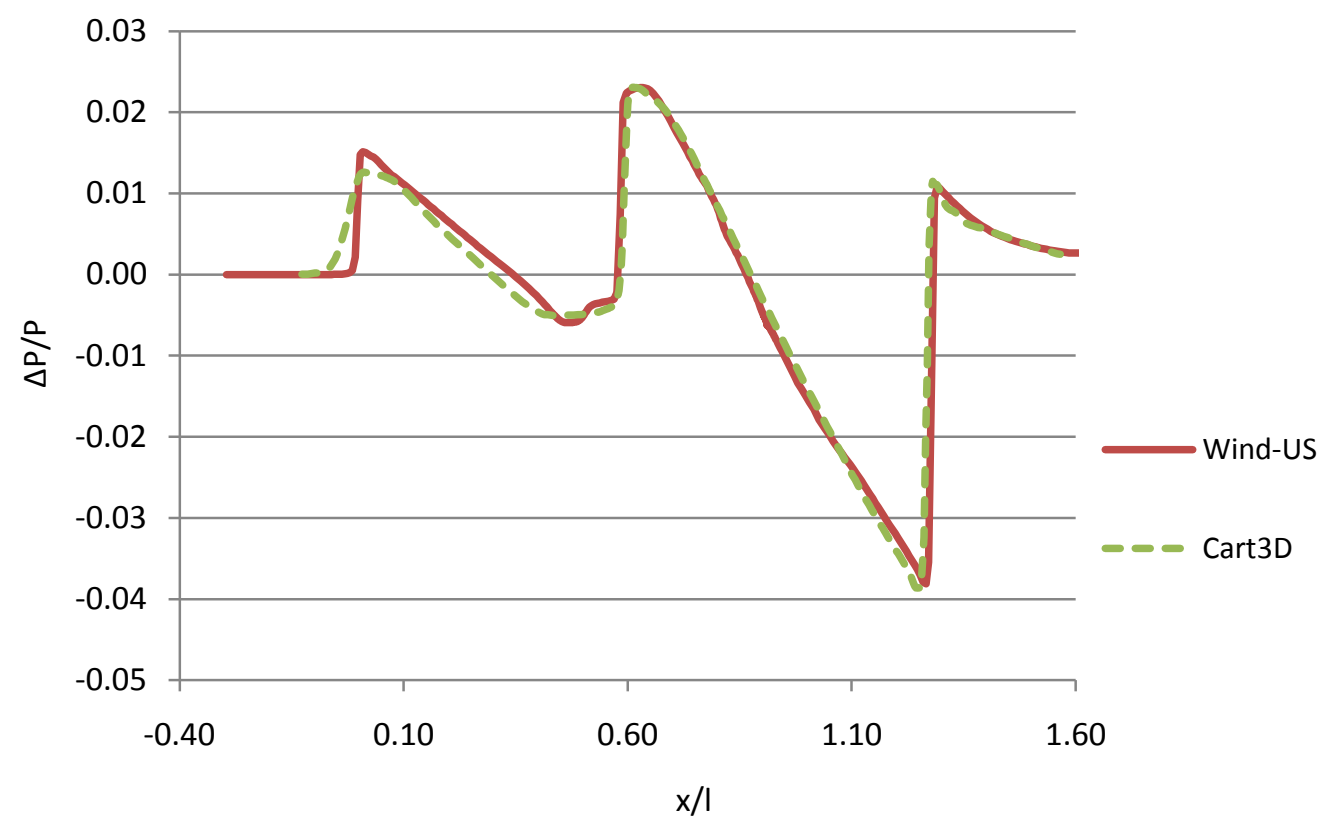

Figure 11. $\Delta \mathrm{P} / \mathrm{P}$ at $\mathrm{h} / \mathrm{l}=3$ for Wind-US and Cart3D solutions, nozzle off, Mach 2.2

V.c. Results for $\mathrm{NPR}=18$ at $\mathrm{M}_{\infty}=2.2$

Results are presented for Mach 2.2 free-stream flow and the nozzle operating at NPR=18. Figure 12 is a plot of Mach number contours along the vertical and horizontal stream-wise center-planes for the wing-body vehicle with the nozzle operating at a NPR of 18. The solutions again display the shock and expansion from the nosecone, followed by the shock and expansion from the wing. Flow around the exhaust nozzle exhibits an expansion from the nozzle boat-tail, followed by a shock at the nozzle lip, similar to previous studies.

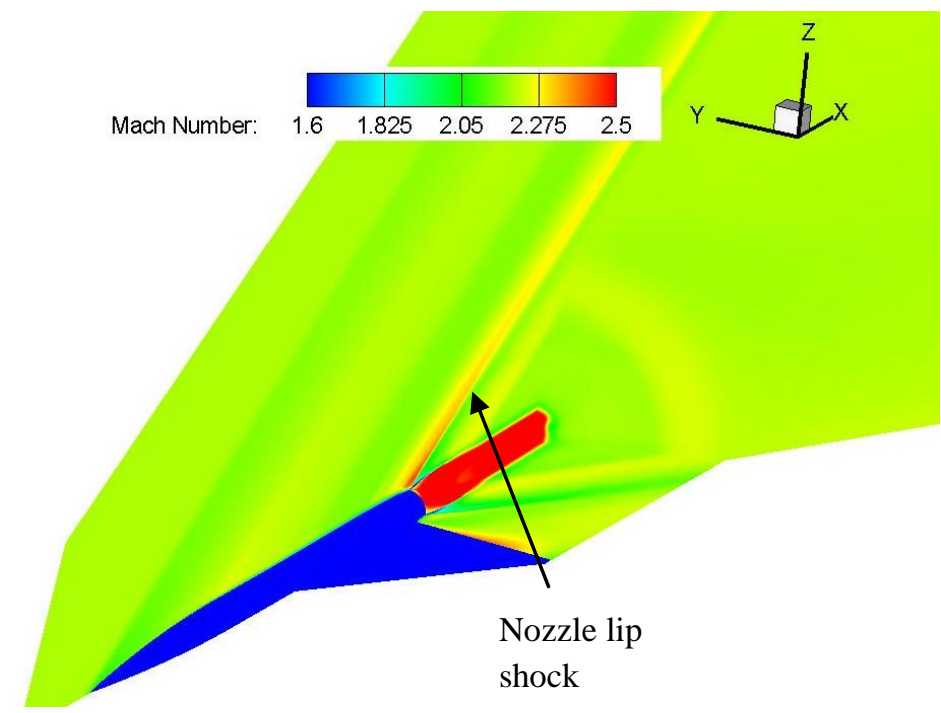

Figure 12.a. Wind-US Mach number contours near vehicle, NPR=18, Mach 2.2 


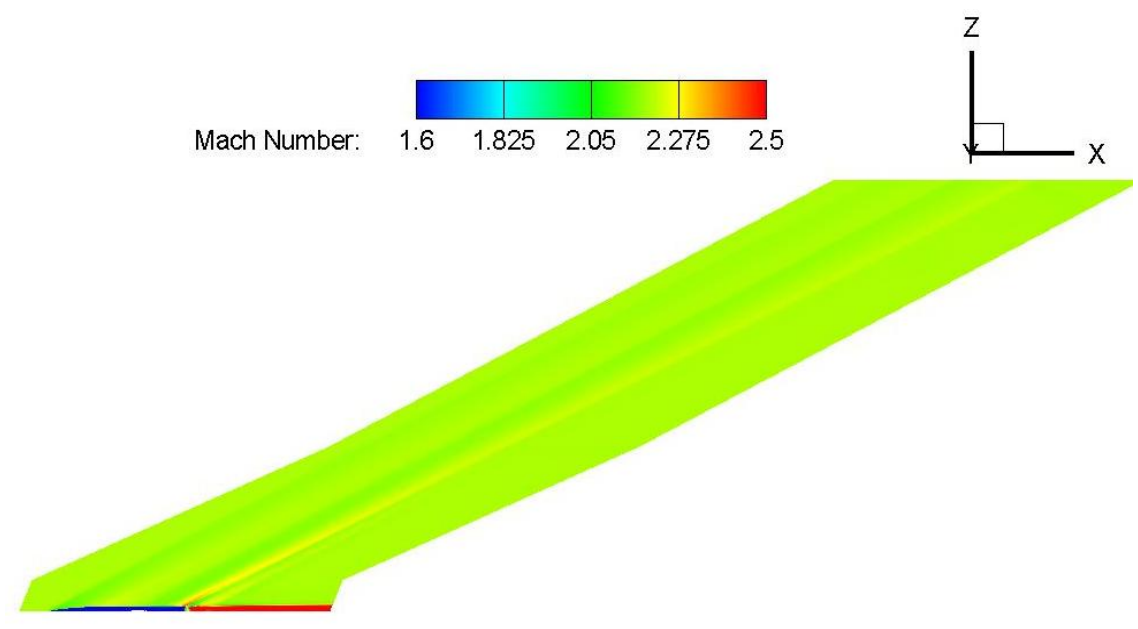

Figure 12.b. Wind-US Mach number contours, NPR = 18, Mach 2.2

The pressure signature at $\mathrm{h} / \mathrm{l}=3$ from the vehicle is displayed in Figure 13. This far field pressure signature also demonstrated the shock and expansion from the nosecone, the wing, and the shock at the nozzle lip. The increase in value for the right hand peak demonstrated how the strong lip shock at the nozzle, due to the underexpanded nozzle plume, suppressed the expansion due to flow around the wing and the nozzle boat-tail. Comparing Figure 11 and Figure 13 , it is observed that the minimum pressure improves from -0.038 to -0.03 due to the shock at the nozzle lip, which suppresses the expansion wave from the vehicle.

The Cart3D solutions for this case were not as straightforward. First, Cart3D was used to compute the exhaust nozzle plume shape, based on boundary conditions placed in the nozzle plenum. Mach number contours for this solution are in Figure 14. The Cart3D solution was an inviscid solution, and computed a larger plume shape, seen in Figure 14.c. The off-body pressure signature for the Cart3D solution with the computed plume is also displayed in Figure 13, where the lower right portion of the signature near $x / l=1.0$ is significantly higher than the Wind-US solution. Based on previous studies, the plume can be replaced with a representative solid body (see Putnam $^{3}$ ). When the plume shape was added behind the vehicle as a solid body, the agreement between the WindUS solution and the Cart3D solution was good, and the resulting pressure profile is also seen in Figure 13. 


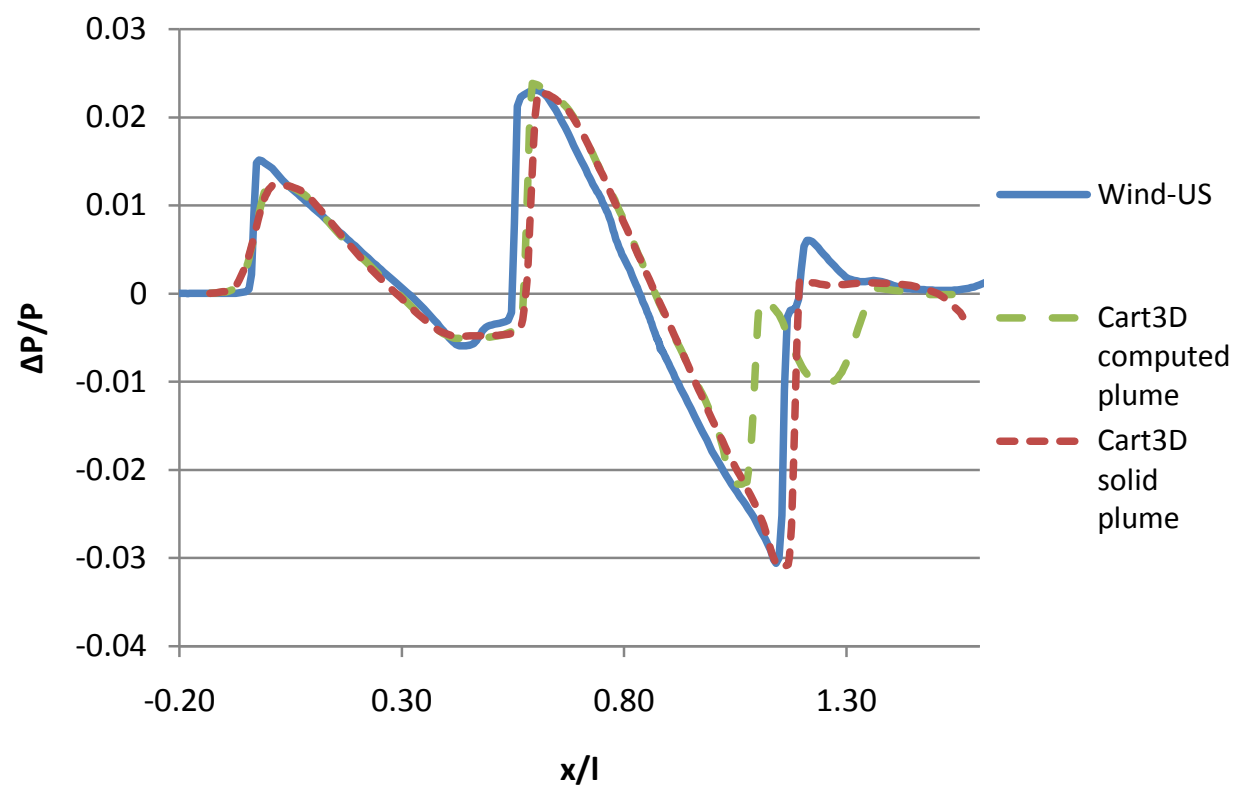

Figure 13. $\Delta \mathrm{P} / \mathrm{P}$ at $\mathrm{h} / \mathrm{l}=3.0$ for Wind-US and Cart3D solutions, nozzle NPR $=18$, Mach 2.2

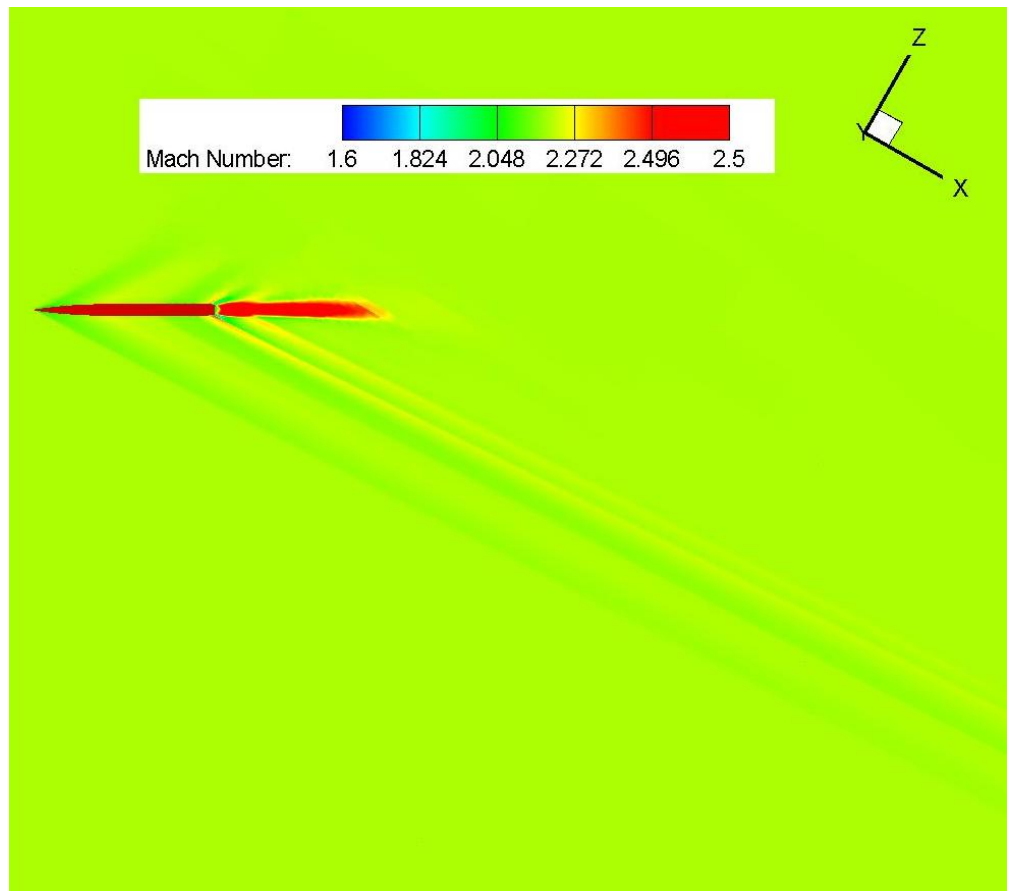

Figure 14.a. Cart3D Mach number contours for 'nozzle on', NPR = 18, Mach 2.2 


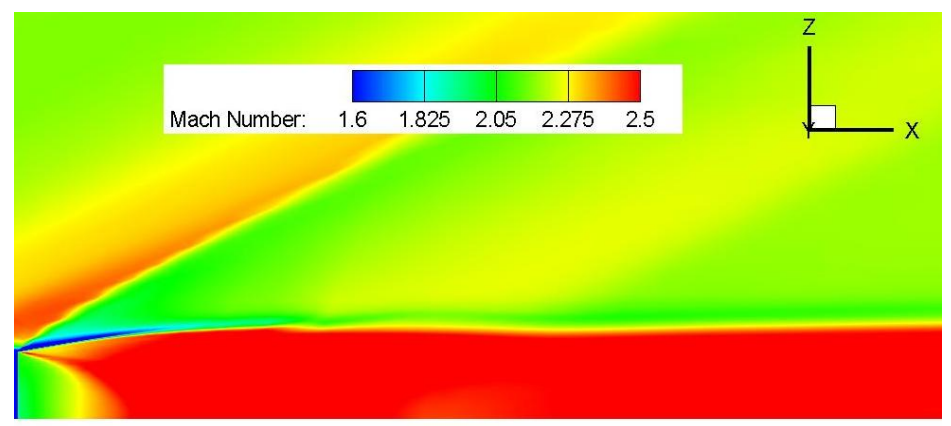

Figure 14b. Wind-US computed plume shape for 'nozzle on', NPR = 18, Mach 2.2

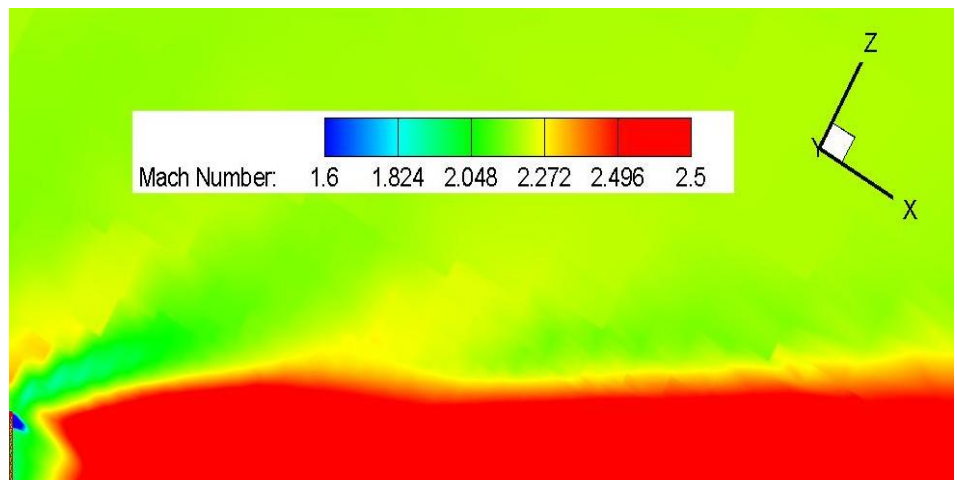

Figure 14.c. Cart3D computed plume shape for 'nozzle on', NPR = 18, Mach 2.2

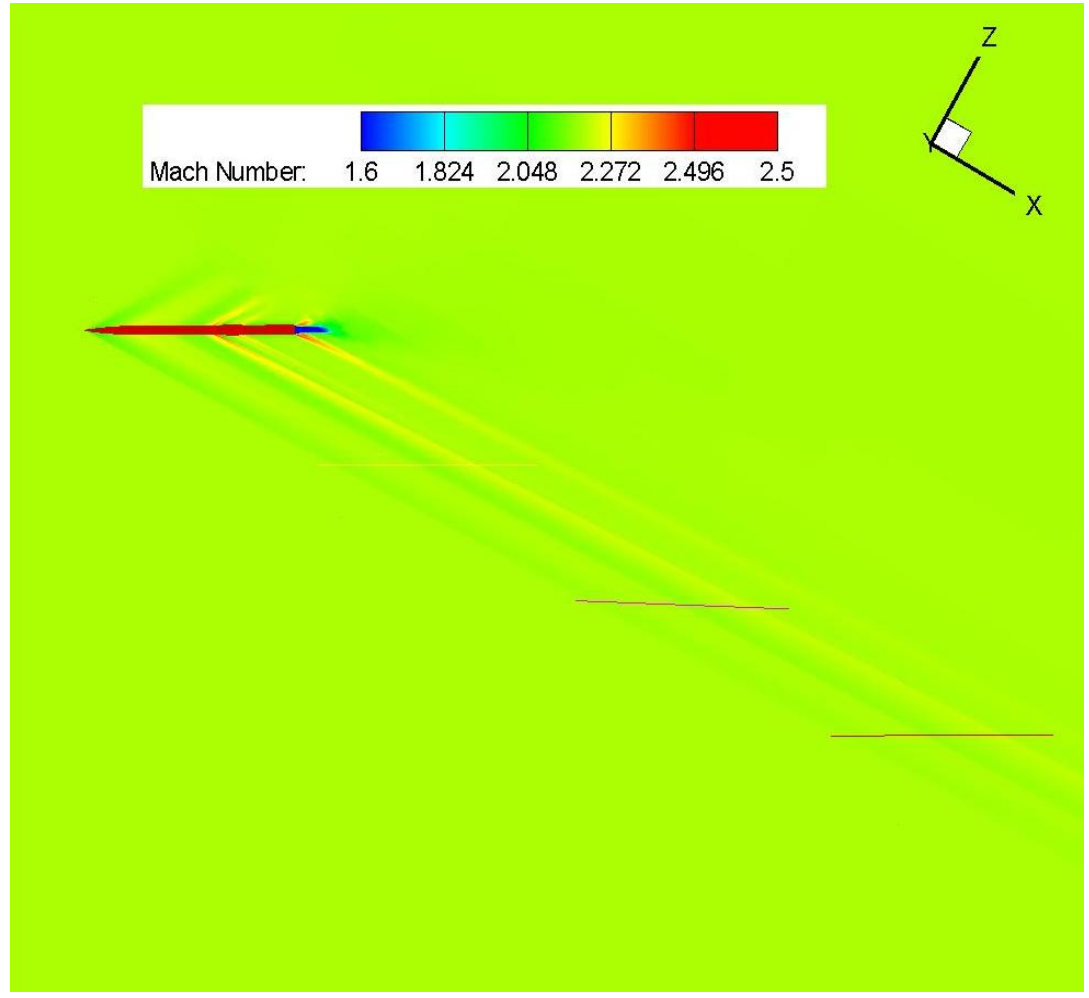

Figure 15. Cart3D Mach number contours for solid modeled nozzle plume, NPR = 18, Mach 2.2 


\section{V.d. PCBoom Extrapolation (Cart3D solutions)}

Pressure signature results for the wing-body vehicle without plume and with NPR=18 are compared to the nozzle design point, NPR=8, as shown in Figure 16. These simulations were computed using the solid-body plume approximation. The pressure signature for the wing-body vehicle with the 'Nozzle 6' operating at it's design point shows some improvement over the case with no plume. However, nozzle operation at NPR=18 offers a more dramatic change in the expansion pressures at the lower right hand portion of the pressure signature.

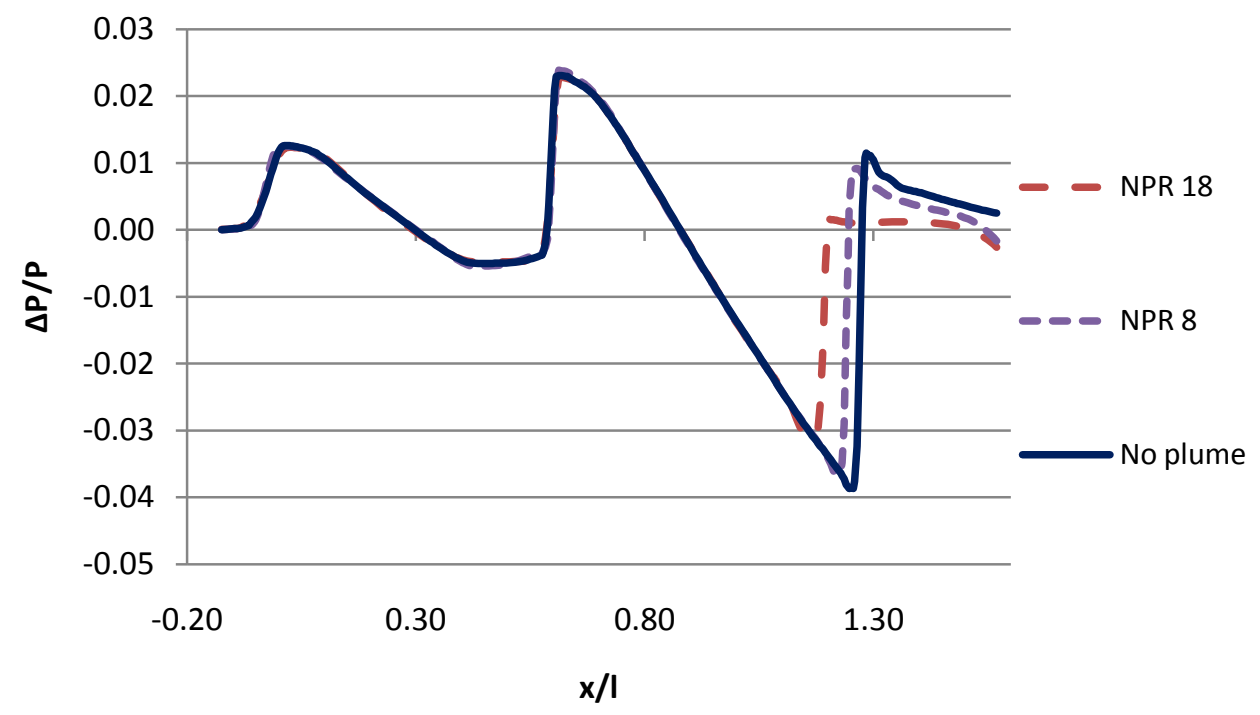

Figure 16. Comparison of Cart3D solutions $(\mathrm{h} / \mathrm{l}=3)$ with no plume, NPR=8 and NPR=18.

PCBoom $^{12}$ was used to extrapolate the pressure signature data from Figure 16 to an estimated ground observed sonic boom signature for the various Cart3D solutions. These results are plotted in Figure 17. The ground signatures demonstrate how the under-expanded nozzle exhaust changed the vehicle right hand portion of the sonic boom signature, and changed the value from -0.921 to -0.808 . This was a $12 \%$ improvement.

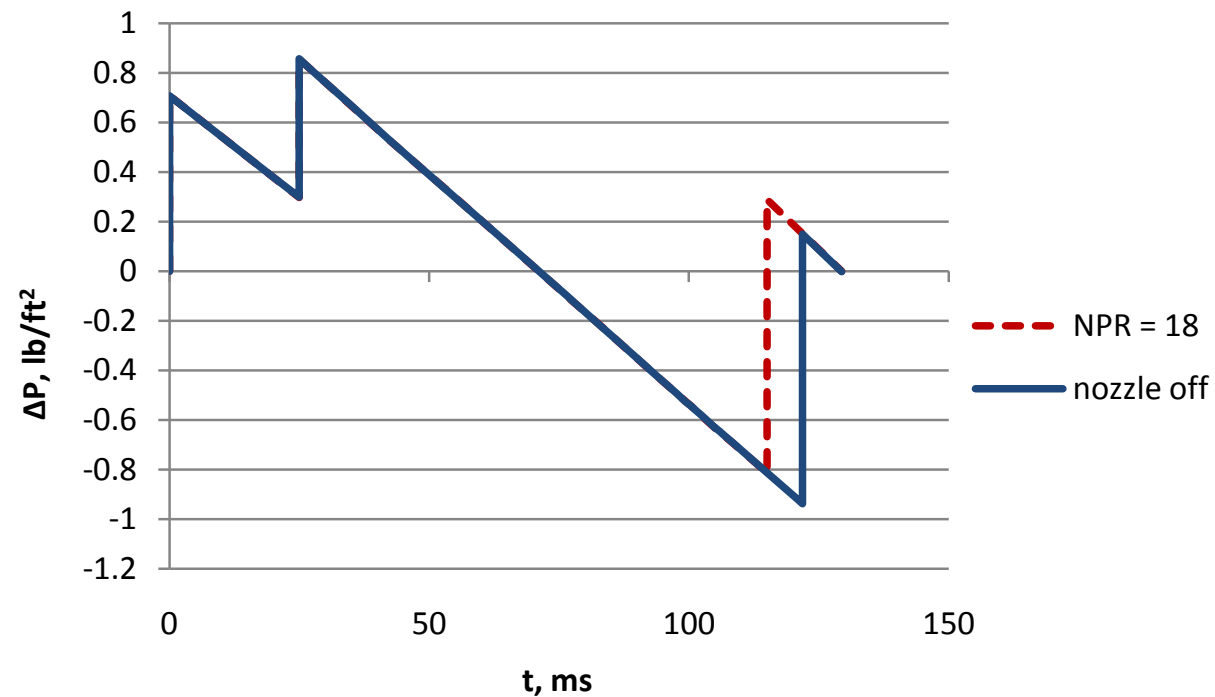

Figure 17. Estimated ground-observed sonic boom signature comparison: Mach 2.2, nozzle off and nozzle NPR =18. 


\section{Conclusions}

The primary goal was to demonstrate the exhaust nozzle plume effect on off-body pressure signatures for a simplified 'single engine' wing-body model. A secondary goal was to demonstrate the use of the Cart3D inviscid code for off-body pressure signatures including the nozzle plume effect, as use of Cart3D had clear benefits of reduced computing time. To perform this simplified study, the $59^{\circ}$ delta wing-body model was selected. The vehicle was analyzed to determine the effects of an exhaust nozzle plume on the overall vehicle pressure signature, and thereby the sonic boom signature. Two CFD codes were used for this analysis, Wind-US and Cart3D. Cart3D had been validated for sonic boom analysis without nozzle plume effects. Wind-US had been extensively validated for use in exhaust nozzle analysis.

It was observed that the shocks from a single nozzle configuration, acting on the center of the vehicle, had a measureable effect on the overall vehicle pressure signature. It is encouraging that the effect of the nozzle plume may be utilized to modify an aircraft sonic boom signature. Future studies will include more realistic engine size and placement to estimate the effects of exhaust nozzle plumes for supersonic transport aircraft. More realistic configurations will also include inlets and a tail, which were neglected here to simplify the problem and study the underlying flow physics. These physics suggest that the placement of the nozzle and the strength of the nozzle shock could be used to suppress the expansion wave off the vehicle, thereby reducing the sonic boom disturbance.

Comparisons for the $59^{\circ}$ delta wing-body model with no nozzle flow at Mach 1.68 and Mach 2.2 were made with solutions generated by Wind-US including viscous effects, and Cart3D, an inviscid code. Results showed that both codes could be used for this problem. For the $59^{\circ}$ delta wing-body model with an exhaust nozzle operating at NPR $=18$, solutions with Cart3D computed an exhaust nozzle plume shape that was too large, affecting the off-body pressure signature at $\mathrm{h} / \mathrm{l}=3.0$. A solid nozzle exhaust plume was then modeled in Cart3D. Results demonstrate that Cart3D could be used for analysis of nozzle plumes with a vehicle, when the plume was modeled as a solid body with the correct under-expanded plume shape.

\section{References}

${ }^{1}$ Graham, D., Dahlin, J., Meredith, and K.,Vadnais, J., “Aerodynamic Design of Shaped Sonic Boom Demonstration Aircraft," AIAA 2005-8, Jan. 2005.

${ }^{2}$ Freund, D., Howe, D., Simmons, F., and Schuester, L., "Quiet Spike Prototype Aerodynamic Characteristics From Flight Test," AIAA 2008-125, Jan. 2005.

${ }^{3}$ Putnam, L. and Capone, F., "Experimental Determination of Equivalent Solid Bodies to Represent Jets Exhausting into a Mach 2.20 External Stream," NASA TN-D-5553, 1969.

${ }^{4}$ Barger, R. L. and Melson, N. D., "Comparison of Jet Plume Shape Predictions and Plume Influence on Sonic Boom Signature," NASA TP-3172, Mar. 1992.

${ }^{5}$ Castner, R. S., "Analysis of Plume Effects on Sonic Boom Signature for Isolated Nozzle Configurations," NASA TM-2008-215414 (AIAA-2008-3729), June 2008.

${ }^{6}$ Bui, T., "CFD Analysis of the Nozzle Jet Plume Effects on Sonic Boom Signature," AIAA-2009-1054, Jan. 2009.

${ }^{7}$ Hunton. L., Hicks, R., and Mendoza, J., "Some Effects of Wing Planform on Sonic Boom," NASA TN-D 7160, Jan. 1973.

${ }^{8}$ Wintzer, M., Nemec, M., and Aftosmis, M., "Adjoint-Based Adaptive Mesh Refinement for Sonic Boom Prediction," AIAA-2008-6593, Aug. 2008.

${ }^{9}$ Bush, R. H., Power, G. D, and Towne, C. E.: WIND: The Production Flow Solver of the NPARC Alliance, AIAA Paper 98-0935, Jan. 1998.

${ }^{10}$ Castner, R. S., "Slot Nozzle Effects for Reduced Sonic Boom on a Generic Supersonic Wing Section," AIAA2010-1386, Jan. 2010.

${ }^{11}$ Plotkin, K., and Grandi, F., "Computer Models for Sonic Boom Analysis: PCBoom4, CABoom, BooMap, CORBoom," Wyle Report WR 02-11, June 2002. 